\title{
The Important Role of the Associative and the Deductive Approaches in the Study of Bioactive Glasses
}

\author{
Wenhao Wang ${ }^{1}$, Zhaohui Zhai ${ }^{2}$, Ruohan Wang ${ }^{1}$, Xiaopei Zhang ${ }^{1}$, Yanyan Li $^{2}$, Yuli Li $^{2 *}$ \\ ${ }^{1}$ Division of Clinical Medicine Science, Weifang Medical University, Weifang, China \\ ${ }^{2}$ Division of Plastic Surgery, Weifang Medical University, Weifang, China \\ Email: $1412039956 @ q q . c o m$
}

\begin{abstract}
The associative and the deductive approaches play an important role in learning activities, which is an indispensable section in the whole process of cognition. This paper discusses the associative and deductive approaches in the study of the bioactive glasses, and analyzes the contingency and inevitability in the research of bioactive glasses. Thus, the philosophy and science as the whole cannot be separated, these two are auxiliary to each other for achieving current success.
\end{abstract}

Keywords: associative approach, deductive approach, bioactive glass, contingency and inevitability.

\section{Introduction}

The bioactive glass was created by Professor Larry L. Hench in the University of Florida, which has been an important component in the inorganic bioactive materials. As the bioactive glass possesses the good biological activity which can form strong chemical bonding, it attracted lots of attentions in the academia.

The bioactive glass was officially started clinical applications in 1985, as a result, numerous patients were cured. The bioactive glass plays the role of milestone in the development of bioactive materials. Looking back to the development history, the first generation of bioactive material is inactive and will generate the host rejection; in the second generation, the biological activity and host will form binding. It can be evidenced that the bioactive glass not only cures the patient but also inspires the bioactive material research. Thus, the bioactive glass development history and philosophical approaches will be illustrated in the following sections.

\section{The Research Question of Bioactive Glass_-Audacious Analogy and Clever Thinking}

There is an interesting story about the invention of bioactive glass, based on the research experiences of professor Larry L. Hench. He started the research from 1957, when he was doing formula research about glass, glaze, enamel and white ceramics in the Ceramic engineering lab of Ohio State University. In 1959, Larry L. Hench did the research about dense aluminum oxide layer inside and outside Jet engine's fuel channels when he was doing his summer internship in CM (General Motors Corporation). Although his research about the jet engine was not released, this research experience interested and inspired him very much. As a result, Larry L. Hench started his research from then on ${ }^{[1]}$.

In 1966, Hench got his first research project which is funded by US Department of Defense, specifically, it was a part of 'unconventional semiconductor' research which is a type of radiation resistance semiconductor material. This type of material can be used as electric switch in the satellite to resist solar flare or radiation from certain types of weapon. In 1967, Hench reported his research achievements in the press conference in U.S. Army Material research institute. Interestingly, the story of the bioactive glass started from the way to this conference, Hench was in the same car with Army Medical Corps back from Vietnam War. At that time, Hench talked about the $\mathrm{V}_{2} \mathrm{O}_{5}-\mathrm{P}_{2} \mathrm{O}_{5}$ experiments under the $\boldsymbol{\gamma}$-ray with US Colonel Klinker, then Klinker asked one question, Hench said that his life was changed by this question, 'if you can create the valid material under the high-energy radiation, could you also create a kind of material which exist inside in the body?'. Hench was very confused by this question and wanted Klinker to explain it more clearly. Klinker witnessed lots of amputation in Vietnam, they have no choices but amputation 
because of the body rejection to surgical metal and plastic parts. Klinker explained that 'we could save life but sometimes we could not save life without amputation, we need a new material without body rejections'. This suggestion motivated Hench to develop a new material which would not form cicatricial tissue in the human tissue, thereby, the bioactive glass was created in this problem.

Colonel Klinker associated the material exposed in the high-energy radiation with the material in human body. These two questions seem like irrelevant, one is about the electric switch in the satellite, the other is about substitute material in human body. However, it is just because of this associative approach, the medical material was developed into a new era, the age of bioactivity. This type of associative approach seems more commonly used by poet and literature, actually, it is also an important creativity and motivation in nature science researches. For example, Einstein took the bus and had a 'daydream' by looking at the bell in the square, which shocked the physics academia; De Broglie as the master in literature and physics academia, by throwing the pebble in the water, he associated it with wave-particle dualism. In 2010, The Wall Street Journal named 17 areas creative awards in tech, in this appraisal, the foldable display panel as thin as paper from Taiwan Industrial Technology Research Institute (ITRI) ranked in the top. The idea of the foldable display panel originally comes from the Taiwan local pancake. This type of pancake can be easily folded in the high temperature, which inspires the researchers. Specially, this technology can be applied in various displayers, including LCD、 LED or next generation OLED displayer and so on. The associative approach indeed made great of contributions to science and technology, in the future, the displayer would be made by this kind of soft material, and could be wrapped like a pen in the pocket, rather than taking with the clumping laptop anymore. Overall, according to these experiences, it can be evidenced that 'Science and technology are the productive forces' from Xiaoping Deng.

\section{The Hypothesis of Bioactive Glass_— the Power from Deductive Logics}

After that conference, Hench got back Florida and discussed this question with his medical school's friend Ray to make sure the human body rejection issues. They got in touched with another two group members, from the department of orthopedics, Ted Greenlee and Bill Allen, and organized a series of seminars to discuss this question, they would like to join this research if the U.S. Army would like to fund this project. In 1968, Hench provide U.S. Army Material research institute and the department of development with a research proposal, it based on a simple hypothesis, 'considering the human body without metal and plastic material, it would form cicatricial tissue in the surgical implants places with metal or plastic materials, the skeleton contains Calcium phosphate hydrate, namely Hydroxyapatite, thus, if the material could form Hydroxyapatite coatings, there would be no body rejections'. This hypothesis uses a deductive approach.

What is deductive approach? The deductive approach is generally defined as logic reasons from the general to the particular, which is also named as inevitable reasoning or faithful reasoning. For example, from the precondition of 'all men must die', the result of 'Socrates will die' can be reasoned. It is not necessary to discuss the deductive logics with inductivist, although the inductivist believes that the deductive reasoning cannot generate new knowledges because its conclusion is included in the preconditions. However, the deductive logic could discover the 'hidden knowledge' within the process of scientific researches, which plays an irreplaceable role. When Chen Ning Yang in his 80 ages, he was still thinking the relationship between science and Chinese traditional culture, instead of deductive logics, there is only inductive logics in I Chinq, he came up that the I Chinq would block the development of science in China. The importance of deductive reasoning cannot be neglected, most of the scientists are doing inductive researches for summarizing the scientific phenomenon into the theory. Thereby, the new knowledge could be inferred from the learned knowledge, the Einstein system is in this way, only the deductive system could achieve this.

In 2010, the Royal Swedish Academy of Sciences announced that they will award the Nobel Prize in Physics to Andre Geim and Konstantin Novoselov who are scientists in University of Manchester, in order to commend their groundbreaking researches in terms of graphene materials, Geim was 52 years old and Novoselov was 36 years old at that time. It is a common household product which is used as the final thin and hardest material, the graphene material is two-dimensional Carbon crystal with high strength and good electrical conductivity, it is almost transparent and the thickness is same as one atom. The graphene maybe the fuel for the Moore's Law, the graphene is commonly regarded as the substitute material of 
Silicon for the next electronic industrial revolution. Although the graphene and diamond are both Carbon crystal, the strength of these two are very different. Specially, the diamond is three-dimensional structure, the graphene is made up by two-dimensional flat sheet of carbon with the carbon atoms arranged in a honeycomb lattice. Since the force between the flat sheets are relatively weak, the graphene easily peels off and forms sheet of carbon. This is reason why the pencil is made up by graphite. The single-layered graphene is super strong sheet of carbon which is only one atom thick. For a long time, since some attempts for making the graphene material were failed, scientists were believing that this kind of two-dimensional crystal material cannot be in stable existence. Until 2004, Geim and his assistant Novoselov discover the graphene and published it in the American Journal of Science, they utilized the scotch tape to paste and peel off over and over again, thereby, the thickness of graphene is gradually reduced, finally, the one atom thick graphene was found under the microscope. This finding broke the theory predicts that there is no existing two-dimensional crystal material in reality. This super strong sheet of material is characterized as high strength and good electrical conductivity, which have attracted much attention of researchers in the worldwide. After fullerene and carbon nanotubes, the graphene material becomes the new milestone.

In 2020, it was not only a special year but also a 'technology year' for China. In the December of 2019, the Corona Virus Disease was firstly found in China Wuhan, it was officially named as COVID-19 in $11^{\text {th }}$ February 2020. The COVID-19 is characterized by fast spread but lack of effective treatments. PCCM specialist Xiaoling $\mathrm{Xu}$ in the first affiliated hospital of USTC (Anhui provincial hospital) and professor Haiming Wei team in USTC Bioscience and Medicine School, they associated this pandemic with two zoonosis Coronavirus in the past ten years, SARS-CoV and MERS-CoV. In the pathogenesis of SARS, it was found that there was a cytokines storm, releasing IL-6, TNF- $\alpha$, IL-12 and many proinflammatory cytokines. In another research of MERS, it is also caused by Coronavirus, proinflammatory cytokines of IL-6, IL-1 $\beta$ and IL-8 are raised dramatically. Considering these two researches, it provided new solutions for the research of COVID-19. After analyzing the immune feature of severe COVID-19 patients, they found that the COVID-19 is similar with those two existing Coronavirus. With the raising of IL-6, GM-CSF and IFN- $\gamma$, the disease-causing T-cell and inflammatory cell with a large amount of IL-6 would cause the inflammation storm. Thus, they thought of Tocilizumab, as a recombinant humanized anti-human IL-6 receptor monoclonal antibody, can bind to the IL-6 receptor with high affinity, thus preventing IL-6 itself from binding to its receptor, rendering it incapable of immune dam-age to target cells, and alleviating the inflammatory response, whereas this type of medicine was used to treat the clinical rheumatoid arthritis. In current, this treatment has been applied and promoted in more than 20 countries, and make contributions on 'China solution' for global pandemics fighting. ${ }^{[2]}$ Association is to associate the current issues with former, similar or opposite things. By using the associative approach, it could develop new things from what in front of us, from one side to other side. Then, new things could be found from the new standpoint of deductive approaches, the creative thinking could be inspired by these two.

\section{The Finding and Development of Bioactive Glass—- the Inevitability in Contingency}

In 1969, the Hench team was funded by the U.S. Army Material research institute and the department of development to test their hypothesis. In the joint efforts of Hench team, they made the first type of bioactive glass, fusion bioactive glass 45S5, vitro tests and in vivo tests showed that 45S5 was free from Ca and $\mathrm{P}$ in the test fluid, and the surface of implants forms Hydroxyapatite coatings ${ }^{[3-4]}$. This type of Hydroxyapatite crystal forms a strong chemical boding interface with collagenous fiber which is generated by osteoblast ${ }^{[3-6]}$. Then, this project was funded by U.S. Army Material research institute and the department of development for 10 vears.

Hench made joint efforts with material scientists, orthopedists, biomechanics researchers, biologists in University of Florida. During this period, they solve series of questions about the bioactive glass:

(1) the surface reaction of bioactive glass

(2) the strength of bioactive glass's osseointegration

(3) the confirmation of bioactive glass's osseointegration

(4) the bonding surface of bioactive glass 
(5) the toxicology and biocompatibility of bioactive glass

Importantly, they opened a new era, the age of bioactivity, for metal materials and high polymer materials, compared with inert materials, they started seeking for new materials which were not easily to generate host rejections. After that, the biomaterial academia likes that one hundred flowers blossom together, and put forth new ideas on the basis of eliminating the false and retaining the true. There have been various clinical applications, such as $45 \mathrm{~S} 5$, Ceravital glass-ceramics, A-W glass-ceramics, Bioverit machinable bioactive glass-ceramic and so on, the scientific researchers are still continuously working on researching new bioactive glasses and bioactive medical materials.

In 1978, most of the problems had been solved at the end of this project, and the $45 \mathrm{~S} 5$ was approved by the U.S. NCPDP to do the clinical test in the University of Florida and London Gug's hospital. Until 1981, Hench still hypothesized that only the calcified tissue can form the bonding with bioactive glass. Occasionally, an experiment changed this hypothesis. When one laboratory technician was doing the bioactive glass toxicology experiments, he accidently put a little parenchyma cells into the bioactive glass, however, the cells were not died. At the same time, Hench realized that there might be some new findings. After that, he conducted large amounts of experiments from this new perspective. In the following papers, Wilson ${ }^{[7]}$ pointed out that the bioactive glass also can form bonding with soft connective tissue in the unmoved surfaces. Then, it developed more researches about the bioactive glass and biocompatibility ${ }^{[7-11]}$. It is surprised that the contingency pushed the scientific development, however, there are also some inevitabilities in the process of development, as this kind of inevitability only favors the prepared mind. From the dialectical materialism standpoint, there is no 'completely inevitability', a specific phenomenon is the synthesis of contingency and inevitability. The contingency is the manifestation and supplement of inevitability. Compared with inevitability, the contingency means that it might happen or not happen. Each phenomenon is not existing by the form of completely inevitability, it appears by the features of individual events. That is, every phenomenon contains contingent factors, thus, the inevitability is manifested through the contingency. In each particular phenomenon, except for the inevitable section, there are some contingent events, the specific phenomenon is the combination of contingent events and inevitable events. Therefore, the contingency supplements the inevitability. Specifically, the contingency is phenomenon, the inevitability is the nature of event. For example, there were indeed certain contingencies that the apple fell off the tree and hit Newton on the head, however, seizing this chance to have some deep thinking was a bit of way of 'Nobel'.

\section{The Future of Bioactive Glass}

From the first generation of bioinert materials to the second generation of bioactive materials, in the biological material industry, the innovation and progress were inspired by Hench and its bioactive glass researches. In 2002, Hench published a paper, 'Third-generation biomedical materials', in Science. This paper mainly discusses the third generation of biological materials including the new bioactive glass, which starts a new research point. It mainly involves stimulation, response, and the third-generation biomedical material for self-repair and regeneration of bone tissue ${ }^{[12]}$. If it could utilize the new biomedicine material preparation and shaping technique, combining the gene transfection, biological assembly technique and surface modification technique with cells. It would be highly possible to provide new solutions and applications for bone-repairing and bone tissue engineering scaffold materials. In terms of the sol-gel systems, used bio-organic template self-assembly and electrospinning to prepare bioactive glass nanospheres and nanofibers, and use gene transfection technologv to achieve precise regulation of cell growth and differentiation at the gene level, through biological assembly and surface modification. The technology further improves the cell-specific recognition characteristics of the material and promotes cell adhesion, migration, proliferation and differentiation. By the 3D printing technique, personalized in manufacturing the artificial bone could be realized to further explore the new bioactive glass nanoparticles and its biological scaffold material, surface properties and the relationship between its microstructure and gene regulations in cells. Also, the new bioactive glass as one of the future development tendencies would provide theoretical basis for Gene-mediated bone bone-repairing materials and its scaffold material preparations. 


\section{Discussion}

The Nobel Laureate, Andre Geim, he was awarded the 'Ig Nobel Prize' in 2000, because of the research about the 'flying frog'. It is a prize which is unofficial selection in the U.S., normally, this prize would be released before the Nobel Prize. The venue for the 'Ig Nobel Prize' ceremony honouring science that "makes you laugh, then makes you think" was Harvard's Sanders Theater. At that time, Geim was personally to accept this prize. In the blog, Zhidong Zhang recalled that in the conference in the UK, Geim was invited to do the presentation, he particularly shared his own experience of 'Ig Nobel Prize' and its 'flying frog' research. Zhidong Zhang commented that the graphene replaces the frog and measure the transport property in the magnetic-field (Hall effect). In fact, the material preparation of graphene is not hard, it merely uses the standard sample method of STM. However, it is the 'Nobel' creative thinking to put the graphene under the magnetic-field and to measure the Hall effect. Therefore, it is very important to have a creative way of thinking, especially for researchers. For the influence of the science fiction in the scientific development and scientific innovation, in the first China Science Conference in 1978, Moruo Guo claimed that the scientific researchers should be not only 'evidence-based conclusions' but also 'flight of fancy'. He also said that

The science also requires the creativity and fancy, which might be able to break the shackles of habit. Actually, there are many fancies in the Creation of the Gods, it has been become the reality in nowadays $[13,14]$.

\section{Conclusion}

For the researcher, it is necessary to break the fixed thinking model, the innovation of scientific researches greatly depends on how much the creativity is released in the way of thinking. Instead of purely pursuing to publish papers in SCI, the final purpose and motivation should be based on solving the practical problems in real life. It is an essential process that transfers science and technology into productivity. The association exert an important influence on the research process. The philosophy and science are combined into the whole, which is lighted up with flashes of wit in the process of scientific research.

Acknowledgements. This work was supported by Key Program of Shandong Provincial Natural Science Foundation (Grant No.ZR2020KE018), the Project of Shandong Province Higher Educational Science and Technology Program (Grant No.J17KA253), Weifang Science and Technology Development Plan (2020YX040), Program of Weifang Medical University Foundation (2019YB030, 2018YB025).

\section{References}

1. Hench L. L. (2006). The story of Bioglass. Journal of materials science. Materials in medicine, 17(11), 967-978. https://doi.org/10.1007/s10856-006-0432-Z

2. Xu, X., Han, M., Li, T., Sun, W., Wang, D., Fu, B., Zhou, Y., Zheng, X., Yang, Y., Li, X., Zhang, X., Pan, A., \& Wei, H. (2020). Effective treatment of severe COVID-19 patients with tocilizumab. Proceedings of the National Academy of Sciences of the United States of America, 117(20), 10970-10975. https://doi.org/10.1073/ pnas. 2005615117

3. Hench, L. L., Clark, A. E., \& Schaake, H. F.. (1972). Effects of microstructure on the radiation stability of amorphous semiconductors. Journal of Non-Crystalline Solids, 8(none), 837-843.

4. Hench, L. L., Splinter, R. J. M. , Allen, W. C. , \& Greenlee, T. K. J. . (1971). Bonding mechanism at interface of ceramic prosthetic materials. Journal of Biomedical Materials Research, 5(6), 117-141.

5. Hench, L. L. , \& Paschall, H. A. . (1974). Histochemical responses at a biomaterial's interface. Journal of Biomedical Materials Research.

6. Hench L L, Paschall H A, Allen W C, et al. Interfacial behavior of ceramics implants [J]. National Bureau of Standards Special Publication, 1975, 415: $19 \sim 35$.

7. Wilson, J., Pigott, G. H. , Schoen, F. J. , \& Hench, L. L. . (1981). Toxicology and biocompatibility of bioglasses. Journal of Biomedical Materials Research, 15(6), 805.

8. Vogel W, Höland W, Naumamm K, et al. Development of machinable bioactive glass-ceramics for medical uses [J]. J Non-Cryst Solids, 1988, 100: 453 460. 
9. Kitsugi, T., Yamamuro, T., Nakamura, T., Kokubo, T., Takagi, M., Shibuya, T., Takeuchi, H., \& Ono, M. (1987). Bonding behavior between two bioactive ceramics in vivo. Journal of biomedical materials research, 21(9), 11091123. https://doi.org/10.1002/jbm.820210905

10. Asikainen, A. J., Hagström, J., Sorsa, T., Noponen, J., Kellomäki, M., Juuti, H., Lindqvist, C., Hietanen, J., \& Suuronen, R. (2007). Soft tissue reactions to bioactive glass 13-93 combined with chitosan. Journal of biomedical materials research. Part A, 83(2), 530-537. https://doi.org/10.1002/jbm.a.31225

11. Eberhard, J., Reimers, N., Dommisch, H., Hacker, J., Freitag, S. , \& Acil, Y. , et al. (2005). The effect of the topical administration of bioactive glass on inflammatory markers of human experimental gingivitis. Biomaterials, 26(13), 1545-1551.

12. Hench, L. L., \& Polak, J. M. (2002). Third-generation biomedical materials. Science (New York, N.Y.), 295(5557), 1014-1017. https://doi.org/10.1126/science.1067404

13. Moruo Guo.(1978) resurgence in science and technology. People's Daily.

14. Hao Zhang. (2007). On the Role of Association and Imagination in Scientific Exploration. Journal of henan normal university (philosophy and social science edition), 34(001), 130-133. 